\title{
Opportunities and Gaps in Primary Care Preventative Health Services for Transgender Patients: A Systematic Review
}

\author{
E. Kale Edmiston, ${ }^{1, *}$ Cameron A. Donald, ${ }^{1-3}$ Alice Rose Sattler, ${ }^{1}$ J. Klint Peebles, ${ }^{4}$ \\ Jesse M. Ehrenfeld, ${ }^{1,5}$ and Kristen Laurel Eckstrand ${ }^{1,6}$
}

\begin{abstract}
Purpose: Transgender people face barriers to accessing healthcare, resulting in population-level disparities in health outcomes. Little research is available to better understand the receipt of primary healthcare among transgender patients or how the rate of receipt of preventive care may differ among transgender populations.

Methods: The medical literature regarding U.S. adult transgender primary healthcare was reviewed using a keyword search strategy: transgender OR transsexual OR transvestite OR gender nonconforming for articles published between January 1, 2001 and June 15, 2015. Studies addressing the following topics as assessed by the Behavioral Risk Factor Surveillance System were extracted for qualitative review: colorectal cancer screenings, mammography or chest/breast tissue examinations, cholesterol and blood pressure screenings, tobacco use and smoking cessation, cervical cancer or human papillomavirus (HPV) screenings, human immunodeficiency virus (HIV), annual flu shot, and insurance coverage.

Results: The search identified 1304 eligible records, of which 41 discussed transgender primary or preventive care. The majority of studies discussed HIV rates or risk behaviors, while fewer articles addressed pelvic examinations, tobacco use, insurance coverage, and cholesterol screenings. No studies addressed mammography or chest/breast tissue examinations, colorectal screenings, or flu shots.

Conclusions: Findings from articles addressing five topics are discussed: HIV, cholesterol screenings, tobacco use, pelvic health, and insurance coverage. Gaps in the extant literature, including the lack of studies of nonbinary people, transgender men of color, and transgender people living outside of large coastal urban centers, are discussed. This review, coincident with other health disparity findings, suggests an urgent need for research that addresses the primary care needs of all transgender and gender nonconforming people.
\end{abstract}

Keywords: HIV; primary care; sexual health; transgender

\section{Introduction}

There are significant disparities in access to and receipt of healthcare among transgender and gender nonconforming populations. Limited availability of appropriate and competent care and differential access to inclusive health insurance perpetuate these disparities and lead to significant morbidity and mortality. ${ }^{1}$ Although much research has focused on the transitionrelated care needs of transgender people, access to primary care is critical and is understudied. ${ }^{2}$ Primary care

\footnotetext{
'Vanderbilt Program for LGBTI Health, Nashville, Tennessee.

${ }^{2}$ Columbia University Program in Narrative Medicine, New York, New York.

${ }^{3}$ University of California San Francisco School of Medicine, San Francisco, California.

${ }^{4}$ Department of Dermatology, University of Wisconsin School of Medicine and Public Health, Madison, Wisconsin.

${ }^{5}$ Vanderbilt University Medical Center, Nashville, Tennessee.

${ }^{6}$ Department of Psychiatry, University of Pittsburgh, Pittsburgh, Pennsylvania.

Portions of this work were presented at the GLMA Annual Meeting in 2014.
}

*Address correspondence to: E. Kale Edmiston, PhD, Vanderbilt Program for LGBTI Health, 319 Light Hall, 116121 st Avenue South, Nashville, TN 37232, E-mail: ekale513@gmail.com

(C) E. Kale Edmiston et al. 2016; Published by Mary Ann Liebert, Inc. This Open Access article is distributed under the terms of the Creative Commons License (http://creativecommons.org/licenses/by/4.0), which permits unrestricted use, distribution, and reproduction in any medium, provided the original work is properly credited. 
is the first point of entry into the healthcare system for most undiagnosed patients and is care that is not differentiated on the basis of problem origin or diagnosis. Primary care encompasses care for most basic medical needs and also includes health education, health maintenance, and disease prevention, in addition to diagnosis and treatment. ${ }^{3}$ Thus, access to primary care is a major determinant of health equity. ${ }^{4}$

Despite data suggesting widespread health disparities, human immunodeficiency virus (HIV) status is perhaps the best-characterized preventable health condition among transgender populations, with multiple studies showing an increased incidence of HIV and acquired immune deficiency syndrome (AIDS) among transgender populations, particularly transgender women of color. ${ }^{5-7}$ High rates of HIV/AIDS among transgender people are likely due to multiple interacting factors, including economic marginalization, social stigma, and limited access to healthcare and HIV screening. ${ }^{8}$ Transgender people are also generally less likely to access preventive health screenings. ${ }^{9}$ The reasons for reduced receipt of preventive health screenings are complex and may be due in part to social and economic marginalization, fear of discrimination, lack of access to providers experienced in treating transgender people, lack of provider awareness of appropriate screening guidelines for transgender people, as well as the absence of evidence-based screening guidelines from expert bodies and professional societies. Systemic barriers and discrimination also contribute to health disparities, as transgender people are more likely to experience violence, homelessness, and unemployment than cisgender people, leading to overall poorer health outcomes. $^{5,6,10-12}$

Reduced access to comprehensive health insurance persists despite recent national efforts to reduce these barriers. Transgender people are more likely to be on public insurance than the general U.S. population, and transgender people on public insurance are more likely to be denied care due to their gender identity than those with private insurance. ${ }^{9,13}$ Among those who do have insurance, coverage is variable based on concordance of sex assigned at birth and gender identity, and type of medical care sought. ${ }^{14}$ Combined with the well-documented delay and avoidance of care due to fear of discrimination, these barriers amplify difficulties transgender individuals face when prioritizing their health. ${ }^{9}$

Although an increasing number of studies demonstrate health disparities among transgender communi- ties, many of these studies were performed at single transgender health centers and/or using local convenience samples that limit the generalizability of the results. Furthermore, while recent reviews have discussed barriers to care for and experience of mental health, no reviews have focused on primary care needs for transgender populations. ${ }^{15,16}$ Reviews of HIV prevalence among transgender people have not included information regarding HIV rates among transgender men. ${ }^{7,17-20}$ Given the nationwide distribution of individuals identifying as transgender and the role of primary care in addressing preventive health, there is a need to better characterize current delivery of care to transgender individuals. In this systematic review, the medical literature regarding primary care among transgender people was reviewed to understand the diverse needs of transgender communities. Specifically, we were interested in key primary care measures as assessed by the Center for Disease Control's Behavioral Risk Factor Surveillance System (BRFSS) and rates of insurance coverage. We were also interested in determining if the literature reflected the diversity of transgender people with regard to race, gender identity, sexual orientation, and geographic location. We hypothesized that the literature would show significant disparities in rates of receipt of primary care, as well as high rates of risk behaviors such as unprotected sex and smoking. Secondarily, we hypothesized that transgender people from rural areas and the South of the United States would be underrepresented in the healthcare literature relative to transgender people from coastal urban areas.

\section{Methods}

Search strategy and selection criteria

We performed a systematic review for all peerreviewed published studies containing information related to healthcare in transgender and gender nonconforming populations. We searched Pubmed and Web of Knowledge using a combined heading search strategy: "transgender" OR "transsexual" OR "transvestite" OR "gender non-conforming" between January 1 , 2001 and June 15, 2015. The search was restricted to publications written in the English language. We reviewed reference lists of retrieved articles to identify other relevant studies for review. We did not include data from abstracts, opinions, reviews, or unpublished studies.

Multiple authors (E.K.E., A.R.S., J.K.P., K.L.E., C.A.D.) reviewed the retrieved studies to first confirm 
that the study did, in fact, discuss transgender populations. Studies were included for analysis if the study was performed in the United States, if the sample consisted of adults (18 years of age or older), and was observational in design. Case studies were not included in the analysis. Given the purpose of the review in examining primary care of transgender individuals, studies assessing any factors related to the following health measures as indicated by BRFSS were included: smoking status, HIV status, colorectal screening (age $>50$ ), mammography (age $>50$ ), breast examination (age $>18$ ), cervical human papillomavirus (HPV) screening (age $>18$ ), cholesterol screening (age $>18$ ), annual flu shot (age $>18$ ), or insurance status. ${ }^{21}$

For each study, we extracted the sample $n$, the location of the study, the percentage of the sample identified as people of color, and the gender identity makeup of the transgender sample, as well as the comparison sample if applicable (cisgender women or cisgender men). We also extracted the study methods (computer-based survey, structured, in-person interview, laboratory testing, including histopathological methods, or chart review) and the primary findings. For primary findings, we extracted and reported odds ratios and $p$-values when available, but, because many studies were observational in nature and thus did not include statistical analyses, we also report mean incidence or prevalence rates as well.

\section{Results}

We identified 2460 studies meeting initial keyword search and eligibility criteria. Three hundred fifteen articles were duplicated in our compiled reference list. Of the remaining 2145 articles assessed, 841 were studies of international samples. One thousand three hundred four studies were assessed for eligibility; 455 did not include data on a distinct transgender sample either because they were (1) unrelated to the transgender community, but were instead studies of cisgender gay, lesbian, and/or bisexual (LGB) people, or (2) did not distinguish between cisgender gay men and transgender women in statistical analysis. An additional 802 did not address primary care. Of the remaining 47 studies, 6 included mixed samples of youth under the age of 18 and adults. Forty-one unique articles were included in our qualitative systematic analysis. The majority $(n=31)$ pertained to HIV prevalence, eight discussed insurance status, eight discussed smoking, two were related to cholesterol screening, and four discussed pelvic examina-
tions/Pap tests, nonexclusively. None of the included studies assessed flu vaccination, colorectal screening, or breast cancer screenings (Fig. 1).

\section{Sample characteristics}

Overall, 2 of the 41 articles included samples that were not exclusively urban dwelling. ${ }^{10,22}$ Twenty-one articles included samples from the West Coast, ${ }^{8,11,23-41} 17$ included samples from the East Coast, ${ }^{12,22,29,38,42-54} 3$ from the Midwest, ${ }^{8,29,38} 3$ from the South, ${ }^{10,55,56}$ and 1 each from Hawaii ${ }^{57}$ or Mountain states ${ }^{29}$ (multiple studies included samples from more than one region). One study included a national sample from an online survey and did not specify the location of participants. ${ }^{58}$

Most studies were conducted in samples of transgender women only $(n=18), 8,11,12,23,30-33,36,37,40,41,43,46,49,53,54,57$ followed by transgender men only $(n=6),{ }^{24,35,42,50,52,58}$ or studies that compared transgender women to transgender men $(n=7){ }^{10,25,26,39,44,45,55}$ Six studies compared either transgender men or transgender women to cisgender people. ${ }^{27,28,38,47,48,56}$ Five studies compared transgender people to cisgender people, but did not specify the gender identity of the transgender group, or used suspect and unreliable measures to determine participant's gender identity (see Discussion section). ${ }^{22,29,34,38,51}$

Excluding the seven studies of transgender women of color that were specifically designed to recruit only Black, Latina, or Two-Spirit individuals, and two studies that did not report the racial composition of their samples, studies of transgender women ranged from $47.8 \%$ to $95 \%$ people of color. Studies of transgender men range from $0.0 \%$ to $47.8 \%$ people of color.

The results for each inclusion category of our search are reported below.

\section{Human immunodeficiency virus}

Overall, studies reported high rates of HIV among transgender women (range: 10-52.4\%). Rates of HIV infection between transgender men and the general population were similar, although some studies reported higher rates (range: $0-11 \%$ ). Studies also found high rates of condomless receptive intercourse (CRI) among both transgender women and transgender men (Table 1).

\section{Cholesterol and blood pressure screenings}

Two studies examined cholesterol or blood pressure (BP). Both were longitudinal studies conducted in California. Neither study found that hormone therapy was 


\section{PRISMA Flow Diagram}
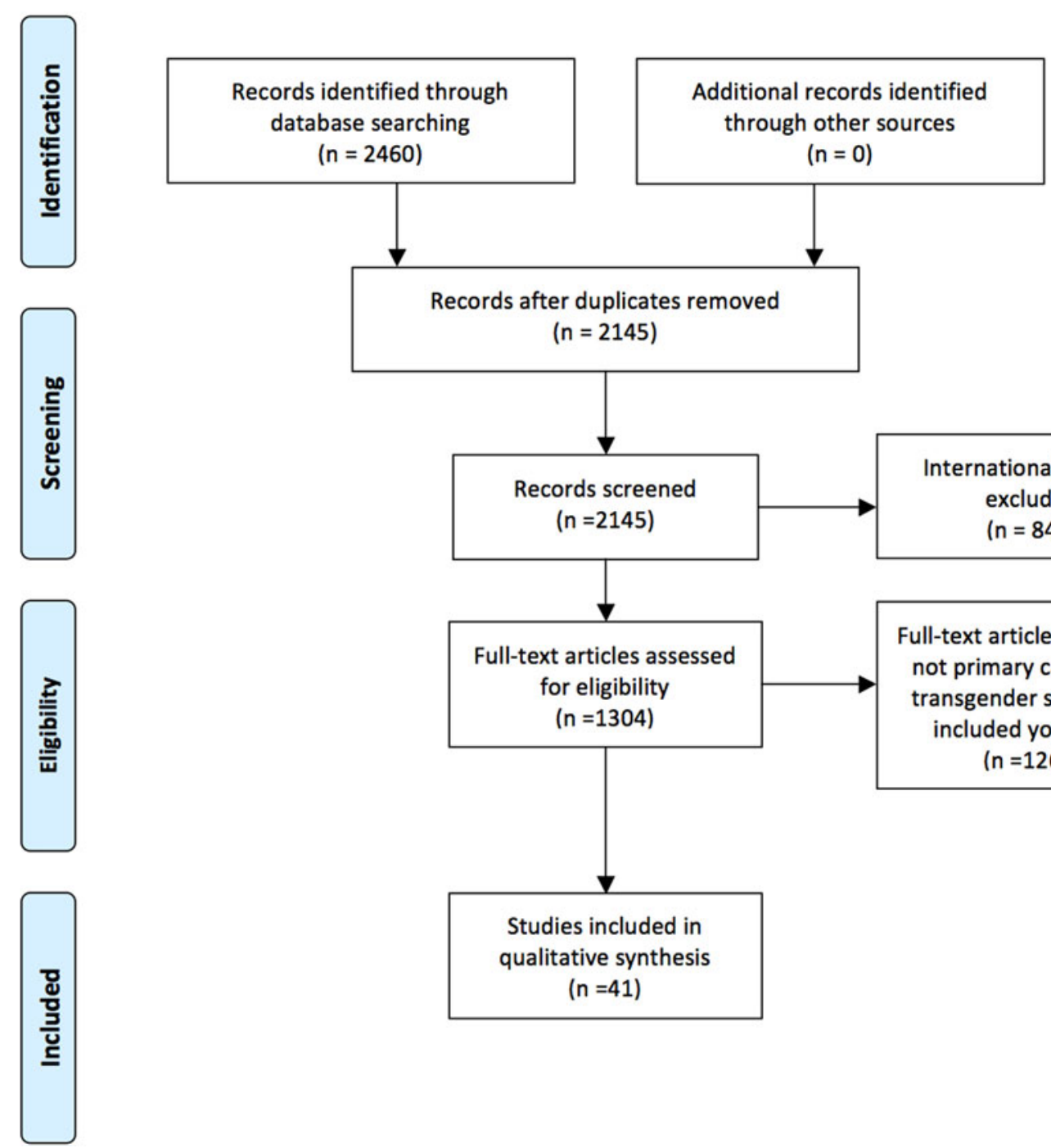

Records after duplicates removed

( $n=2145)$
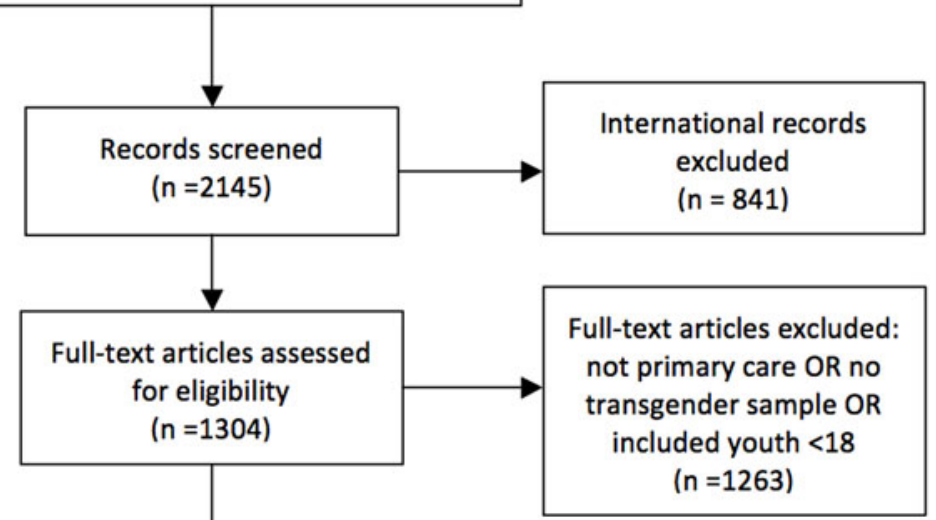

FIG. 1. PRISMA flow diagram. From Moher D, Liberati A, Tetzlaff J, Altman DG, The PRISMA Group. Preferred Reporting Items for Systematic Reviews and Meta-Analyses: The PRISMA Statement. PLoS Med.

2009;6:e1000097. DOI:10.1371/journal.pmed1000097.

associated with clinically significant increases in cholesterol levels or BP (Table 2). ${ }^{26,34}$

\section{Smoking status}

We identified eight relevant articles on tobacco use or smoking status. Most studies reported high rates of tobacco use among transgender people (Table 3). The only study that compared rates of tobacco use among transgender people to a population-based sample of cisgender people found higher rates of smoking among transgender people, ${ }^{22}$ whereas the studies that compared smoking rates among transgender people to cisgender LGB people did not find statistically significant differences in rates of smoking. ${ }^{29,51,56}$ 

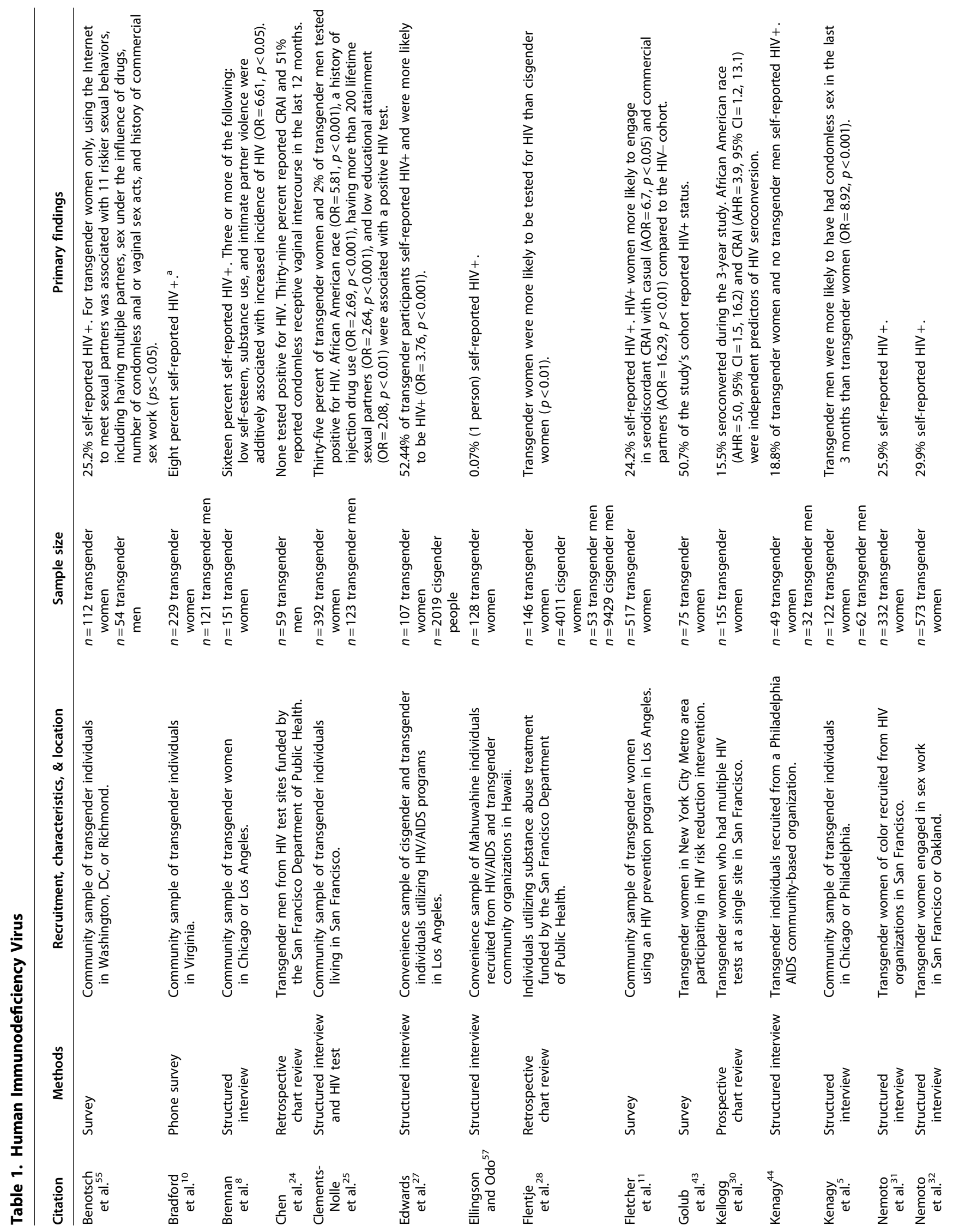


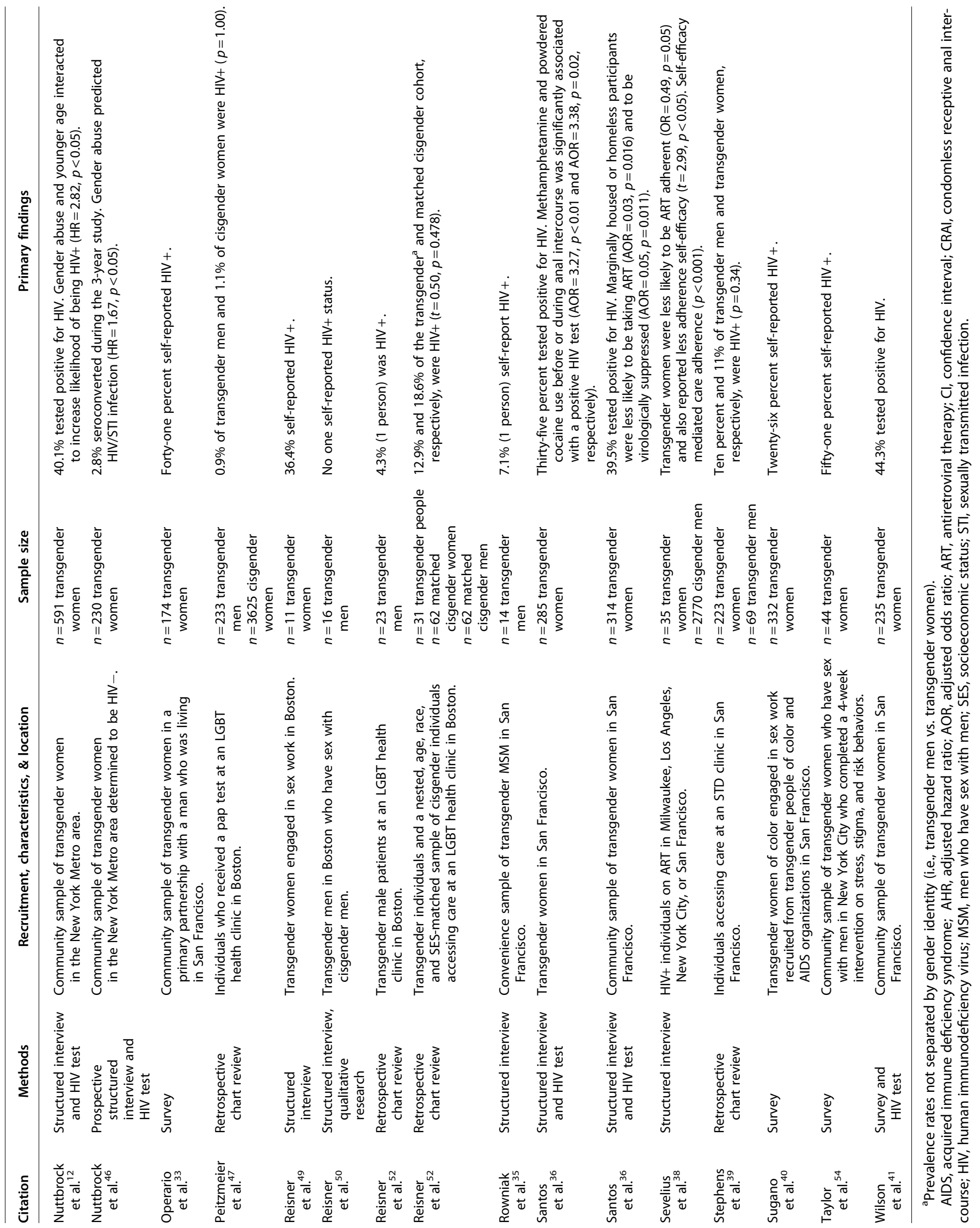


Table 2. Cholesterol and Blood Pressure

\begin{tabular}{|c|c|c|c|c|}
\hline Citation & Methods & $\begin{array}{c}\text { Recruitment, } \\
\text { characteristics, \& location }\end{array}$ & Sample size & Primary findings \\
\hline $\begin{array}{l}\text { Deutsch } \\
\text { et al. }^{26}\end{array}$ & $\begin{array}{l}\text { Longitudinal } \\
\text { study, laboratory } \\
\text { findings }\end{array}$ & $\begin{array}{l}\text { Transgender individuals } \\
\text { beginning cross-gender } \\
\text { hormone therapy at an LGBT } \\
\text { health clinic in Los Angeles. }\end{array}$ & $\begin{array}{l}n=16 \text { transgender women } \\
n=31 \text { transgender men }\end{array}$ & $\begin{array}{l}\text { For transgender women, estrogen } \\
\text { therapy was associated with } \\
\text { lower blood pressure (systolic, } \\
p=0.006 \text { and diastolic } p=0.001 \text { ) } \\
\text { as well as increased triglyceride } \\
\text { ( } p=0.013) \text { and HDL ( } p=0.049), \\
\text { but not LDL levels or weight } \\
\text { ( } p \text { s }>0.05) \text {. Transgender men } \\
\text { only had a significant increase in } \\
\text { weight }(p=0.024)\end{array}$ \\
\hline $\begin{array}{l}\text { Roberts } \\
\text { et al. }\end{array}$ & $\begin{array}{l}\text { Chart review } \\
\text { of laboratory } \\
\text { findings }\end{array}$ & $\begin{array}{l}\text { Transgender individuals on } \\
\text { cross-gender hormone therapy } \\
\text { for more than } 6 \text { months } \\
\text { accessing care at a clinic } \\
\text { in San Francisco. }\end{array}$ & $\begin{array}{l}n=55 \text { transgender women } \\
n=20 \text { cisgender women } \\
n=20 \text { cisgender men }\end{array}$ & $\begin{array}{l}\text { LDL levels in transgender women } \\
\text { were lower than those for } \\
\text { cisgender men }(p<0.01) \text { and } \\
\text { more closely resembled } \\
\text { cisgender women. Triglyceride } \\
\text { levels were higher than both } \\
\text { cisgender men }(p<0.01) \text { and } \\
\text { cisgender women }(p<0.005) \text {. }\end{array}$ \\
\hline
\end{tabular}

HDL, high-density lipoprotein; LDL, low-density lipoprotein.

Table 3. Tobacco Use

\begin{tabular}{|c|c|c|c|c|}
\hline Citation & Methods & $\begin{array}{c}\text { Recruitment, characteristics, \& } \\
\text { location }\end{array}$ & Sample size & Primary findings \\
\hline Bradford et al. ${ }^{10}$ & Phone survey & $\begin{array}{l}\text { Community sample of } \\
\text { transgender } \\
\text { individuals in Virginia. }\end{array}$ & $\begin{array}{l}n=229 \text { transgender women } \\
n=121 \text { transgender men }\end{array}$ & $\begin{array}{l}\text { Sixty-four percent reported lifetime } \\
\text { tobacco use and } 13 \% \text { reported } \\
\text { current use. Reporting a "problem } \\
\text { with tobacco" was associated with } \\
\text { experiencing discrimination } \\
(\mathrm{AOR}=1.33, p=0.03) .^{\mathrm{a}}\end{array}$ \\
\hline Conron et al. ${ }^{22}$ & Phone survey & $\begin{array}{l}\text { Community sample of cisgender } \\
\text { and transgender individuals in } \\
\text { Massachusetts. }\end{array}$ & $\begin{array}{l}n=131 \text { transgender people } \\
n=28,045 \text { cisgender people }\end{array}$ & $\begin{array}{l}\text { Transgender }(36.2 \%) \text { sample more } \\
\text { likely to be a current smoker than } \\
\text { cisgender }(17.3 \%) \text { sample }\left(\chi^{2}=7.19\right. \\
p<0.01) .^{a}\end{array}$ \\
\hline $\begin{array}{l}\text { Johnson- } \\
\text { Jennings } \\
\text { et al. }^{29}\end{array}$ & Survey & $\begin{array}{l}\text { Two-spirit American Indian } \\
\text { individuals from Seattle, San } \\
\text { Francisco, Los Angeles, Denver, } \\
\text { Tulsa, Minneapolis, or } \\
\text { New York City. }\end{array}$ & $\begin{array}{l}n=70 \text { transgender people } \\
n=202 \text { cisgender gay/lesbian } \\
\quad \text { people } \\
n=129 \text { bisexual people }\end{array}$ & $\begin{array}{l}45.2 \% \text { of two-spirit individuals reported } \\
\text { daily smoking. Daily smoking was } \\
\text { correlated with higher reported } \\
\text { stress due to experiences of racial } \\
\text { discrimination in the transgender } \\
\text { group ( } r=0.12, p<0.05) \text {. }\end{array}$ \\
\hline Light et al. ${ }^{58}$ & Online survey & $\begin{array}{l}\text { Convenience sample of transgender } \\
\text { men who had experienced } \\
\text { pregnancy after transition. }\end{array}$ & $\begin{array}{l}n=41 \text { transgender men } \\
\text { and nonbinary people } \\
\text { assigned female at birth }\end{array}$ & $\begin{array}{l}7.3 \% \text { reported smoking during their } \\
\text { pregnancy. }\end{array}$ \\
\hline Reisner et al. ${ }^{52}$ & $\begin{array}{l}\text { Retrospective } \\
\text { chart review }\end{array}$ & $\begin{array}{l}\text { Transgender male patients at an } \\
\text { LGBT health clinic in Boston. }\end{array}$ & $n=23$ transgender men & $\begin{array}{l}\text { Thirteen percent reported current } \\
\text { tobacco use. }\end{array}$ \\
\hline Reisner et al. ${ }^{52}$ & $\begin{array}{l}\text { Retrospective } \\
\text { chart review }\end{array}$ & $\begin{array}{l}\text { Transgender individuals and a } \\
\text { nested, age, race, and SES- } \\
\text { matched sample of cisgender } \\
\text { individuals accessing care at an } \\
\text { LGBT health clinic in Boston. }\end{array}$ & $\begin{array}{l}n=31 \text { transgender people } \\
n=62 \text { matched cisgender women } \\
n=62 \text { matched cisgender men }\end{array}$ & $\begin{array}{l}\text { Smoking prevalence did not differ } \\
\text { between transgender }(54.8 \%) \text { and } \\
\text { matched cisgender }(59.7 \%) \\
\text { participants }\left(\chi^{2}=0.25, p=0.620\right) \text {. }\end{array}$ \\
\hline Sanchez et al. ${ }^{53}$ & $\begin{array}{l}\text { Structured } \\
\text { interview }\end{array}$ & $\begin{array}{l}\text { Transgender women in New York } \\
\text { City recruited from HIV/AIDS } \\
\text { nonprofit organizations. }\end{array}$ & $n=101$ transgender women & $\begin{array}{l}\text { Fifty percent reported current tobacco } \\
\text { use. Participants with a regular } \\
\text { healthcare provider were less likely } \\
\text { to be current smokers }(p<0.004) \text {. }\end{array}$ \\
\hline $\begin{array}{l}\text { Tamí-Maury } \\
\text { et al. }^{56}\end{array}$ & Survey & $\begin{array}{l}\text { Convenience sample of LGBT } \\
\text { individuals recruited at a } \\
\text { Houston Pride festival. }\end{array}$ & $\begin{array}{l}n=5 \text { transgender people } \\
n=45 \text { cisgender males } \\
n=44 \text { cisgender females }\end{array}$ & $\begin{array}{l}\text { Four of } 5 \text { transgender respondents } \\
\text { reported current tobacco use. No } \\
\text { statistical test performed due to } \\
\text { small transgender sample size. }\end{array}$ \\
\hline
\end{tabular}

${ }^{\text {a}}$ Rates not separated by gender identity (i.e., transgender men vs. transgender women). 
Pelvic health screenings

Four articles addressed Pap tests. Two of these studies assessed self-reported rates of lifetime ${ }^{42}$ or recent screenings ${ }^{50}$ in samples of only transgender men or nonbinary people assigned female at birth. The other two articles compared transgender men to cisgender women, with both finding that transgender men were less likely to be up-to-date on Pap tests (Table 4). ${ }^{47,48}$

\section{Insurance status}

Eight articles assessed insurance status of transgender individuals as secondary research questions part of a larger study. Ranges for insurance coverage varied widely (28.0-90.7\% reporting coverage, Table 5).

\section{Discussion}

Overall trends

Forty-one unique articles addressed primary care concerns among transgender people. The majority of articles were related to HIV prevalence or risk factors. Careful examination of the sample characteristics reveals several gaps in the literature, discussed below.

\section{Terminology and language}

Four hundred studies were removed from the initial search that erroneously used the keyword "transgender" to describe cisgender LGB people. Describing samples as LGBT inclusive when these samples do not include transgender people reinforces the idea that the health concerns of transgender people are equivalent to those of cisgender LGB people and promotes the incorrect assumption that transgender people cannot also be lesbian, gay, or bisexual. The majority of studies identified transgender people using the now-standard two question approach, which asks "What sex were you assigned at birth OR What was your sex at birth?" and then "What is your current gender?" This two-part question system allows transgender people to correctly identify themselves with minimal confusion. ${ }^{59}$ However, one study that used a phone survey method used "sound of voice" over the phone to determine gender identity, but only for transgender, not cisgender, participants. ${ }^{22}$ Using such a method confounds the validity of the results and underscores the need for consistent reliable methodology in conducting research among transgender individuals. Researchers should take care to accurately describe their sample with regard to sexual orientation and gender identity; this practice begins at study design.
Several studies combined samples of transgender men and transgender women. ${ }^{10,51}$ Although this practice is understandable given limited sample sizes, findings from studies that do not report outcomes or prevalence rates by gender identity are difficult to apply in clinical settings. In general, there is a much smaller literature regarding transgender men. More research should focus on transgender men to better understand their healthcare needs. Furthermore, no study to date has addressed the needs of nonbinary people or the needs of gender nonconforming people. Some studies have included nonbinary people in their samples of transgender men; however, these studies' small sample sizes limit statistical inference. ${ }^{42,58}$ There is a need for studies designed specifically to recruit nonbinary people to assess rates of receipt of primary care, health disparities, and general experiences with healthcare systems.

\section{Population characteristics}

All but two of the studies in this review were conducted in exclusively urban samples. Because health disparities in general are larger for those living in rural areas, ${ }^{60}$ it is likely that transgender people living in rural areas also experience great health disparities. Furthermore, low population density may increase isolation for transgender people and limit access to providers experienced with caring for transgender patients. Only three studies contained samples of transgender people living in the South of the United States. Given the significant regional cultural differences in the United States, particularly regarding religiosity and acceptance of LGBT people ${ }^{61}$ transgender people living in the South of the United States likely face significant barriers to accessing primary care, as well as high levels of discrimination and isolation. ${ }^{62}$ Studies of transgender people outside of coastal cities are an important opportunity for future research.

Studies of transgender men contained higher percentages of white participants than studies of transgender women. This points to a gap in the literature regarding the experiences of transgender men of color. This gap may be in part explained by gender differences in study design. Many of the studies of transgender men use chart review methods, while more of the studies that used surveys were of transgender women, with recruitment strategies that focused on low-income women of color due to a focus on HIV/ AIDS. Thus, much of the literature regarding transgender men emphasizes the experiences of those who 
Table 4. Pelvic Health

\begin{tabular}{|c|c|c|c|c|}
\hline Citation & Methods & Recruitment, characteristics, \& location & Sample size & Primary findings \\
\hline $\begin{array}{l}\text { Dutton } \\
\text { et al. }{ }^{42}\end{array}$ & Interview & $\begin{array}{l}\text { Convenience sample of transgender } \\
\text { men in New Haven, CT. }\end{array}$ & $\begin{array}{l}n=6 \text { transgender men or } \\
\text { nonbinary people assigned } \\
\text { female sex at birth }\end{array}$ & $\begin{array}{l}\text { Five of } 6 \text { reported receiving a } \\
\text { lifetime pelvic examination. }\end{array}$ \\
\hline $\begin{array}{l}\text { Peitzmeier } \\
\text { et al. }{ }^{47}\end{array}$ & $\begin{array}{l}\text { Retrospective } \\
\text { chart review }\end{array}$ & $\begin{array}{l}\text { HIV individuals with a cervix who } \\
\text { received care at an LGBT health } \\
\text { clinic in Boston. }\end{array}$ & $\begin{array}{l}n=350 \text { transgender men } \\
n=4882 \text { cisgender women }\end{array}$ & $\begin{array}{l}\text { Transgender individuals were } \\
\text { less likely to be up-to-date } \\
\text { on Pap screenings than } \\
\text { cisgender individuals } \\
(\mathrm{AOR}=0.63, p<0.01) \text {. }\end{array}$ \\
\hline $\begin{array}{l}\text { Peitzmeier } \\
\text { et al. }{ }^{47}\end{array}$ & $\begin{array}{l}\text { Retrospective } \\
\text { chart review }\end{array}$ & $\begin{array}{l}\text { Individuals who received a pap test } \\
\text { at an LGBT health clinic in Boston. }\end{array}$ & $\begin{array}{l}n=233 \text { transgender men } \\
n=3625 \text { cisgender women }\end{array}$ & $\begin{array}{l}\text { Transgender men were more } \\
\text { likely to have an inadequate } \\
\text { Pap than cisgender women } \\
(\mathrm{AOR}=10.77, p<0.0001) \text {. } \\
\text { Time on testosterone was } \\
\text { associated with higher rates of } \\
\text { inadequate Pap for transgender } \\
\text { men (AOR }=1.19, p=0.01) \text {. The } \\
\text { relationship between transgender } \\
\text { identity and inadequate pap } \\
\text { remained when controlling for } \\
\text { testosterone therapy (AOR }=6.01 \text {, } \\
p<0.0001) \text {. }\end{array}$ \\
\hline $\begin{array}{l}\text { Reisner } \\
\text { et al. }^{50}\end{array}$ & $\begin{array}{l}\text { Structured interview, } \\
\text { qualitative research }\end{array}$ & $\begin{array}{c}\text { Transgender men in Boston who } \\
\text { have sex with cisgender men. }\end{array}$ & $n=16$ transgender men & $\begin{array}{l}68.8 \% \text { reported a Pap test in the } \\
\text { last } 12 \text { months. }\end{array}$ \\
\hline
\end{tabular}

Table 5. Insurance

\begin{tabular}{|c|c|c|c|c|}
\hline Citation & Methods & Recruitment, characteristics, \& location & Sample size & Primary findings \\
\hline $\begin{array}{l}\text { Bazargan and } \\
\text { Galvan }^{23}\end{array}$ & Structured interview & $\begin{array}{l}\text { Community sample of low-income } \\
\text { transgender Latina women in } \\
\text { Los Angeles. }\end{array}$ & $\begin{array}{l}n=220 \text { transgender } \\
\text { women }\end{array}$ & $\begin{array}{l}28.0 \% \text { reported health } \\
\text { insurance coverage. }\end{array}$ \\
\hline Bradford et al. ${ }^{10}$ & Phone survey & $\begin{array}{l}\text { Community sample of transgender } \\
\text { individuals in Virginia. }\end{array}$ & $\begin{array}{l}n=229 \text { transgender } \\
\quad \text { women } \\
n=121 \text { transgender men }\end{array}$ & $\begin{array}{l}70.9 \% \text { reported health } \\
\text { insurance coverage. }\end{array}$ \\
\hline Chen et al. $^{24}$ & $\begin{array}{l}\text { Retrospective chart } \\
\text { review }\end{array}$ & $\begin{array}{l}\text { Transgender men from HIV test } \\
\text { sites funded by the San } \\
\text { Francisco Department of } \\
\text { Public Health. }\end{array}$ & $n=59$ transgender men & $\begin{array}{l}52.5 \% \text { reported health } \\
\text { insurance coverage. }\end{array}$ \\
\hline Conron et al. ${ }^{22}$ & Phone survey & $\begin{array}{l}\text { Community sample of cisgender } \\
\text { and transgender individuals } \\
\text { in Massachusetts. }\end{array}$ & $\begin{array}{l}n=131 \text { transgender } \\
\text { people } \\
n=28,045 \text { cisgender } \\
\text { people }\end{array}$ & $\begin{array}{l}86.2 \% \text { of transgender people } \\
\text { reported health insurance } \\
\text { coverage. } 22.8 \% \text { of } \\
\text { transgender people reported } \\
\text { public health insurance } \\
\text { coverage. }^{\text {a }} \text { There were no } \\
\text { differences in insurance } \\
\text { coverage between transgender } \\
\text { and cisgender people } \\
\text { (all } p s>0.50) \text {. }\end{array}$ \\
\hline $\begin{array}{l}\text { Peitzmeier } \\
\text { et al. }{ }^{47}\end{array}$ & $\begin{array}{l}\text { Retrospective chart } \\
\text { review }\end{array}$ & $\begin{array}{l}\text { Individuals who received a pap } \\
\text { test at an LGBT health clinic } \\
\text { in Boston. }\end{array}$ & $\begin{array}{l}n=233 \text { transgender } \\
\text { men } \\
n=3625 \text { cisgender } \\
\text { women }\end{array}$ & $\begin{array}{l}90.7 \% \text { of transgender men had } \\
\text { health insurance coverage. } \\
\text { Rates of insurance coverage } \\
\text { did not differ between } \\
\text { cisgender and transgender } \\
\text { people }(p=0.88) \text {. }\end{array}$ \\
\hline Reisner et al. $^{50}$ & $\begin{array}{l}\text { Structured interview, } \\
\text { qualitative research }\end{array}$ & $\begin{array}{l}\text { Transgender men in Boston who } \\
\text { have sex with cisgender men. }\end{array}$ & $n=16$ transgender men & $\begin{array}{l}75.0 \% \text { reported health insurance } \\
\text { coverage. }\end{array}$ \\
\hline Sanchez ${ }^{53}$ & Structured interview & $\begin{array}{l}\text { Transgender women in New York } \\
\text { City recruited from HIV/AIDS } \\
\text { nonprofit organizations. }\end{array}$ & $\begin{array}{l}n=101 \text { transgender } \\
\text { women }\end{array}$ & $\begin{array}{l}77.2 \% \text { reported health insurance } \\
\text { coverage. } 69.2 \% \text { of those with } \\
\text { insurance had Medicaid. }\end{array}$ \\
\hline Santos et al. ${ }^{36}$ & $\begin{array}{l}\text { Structured interview } \\
\text { and HIV test }\end{array}$ & $\begin{array}{l}\text { Community sample of transgender } \\
\text { women in San Francisco. }\end{array}$ & $\begin{array}{l}n=314 \text { transgender } \\
\text { women }\end{array}$ & $\begin{array}{l}\text { Health insurance status was not } \\
\text { associated with ART use } \\
\text { among HIV+ transgender } \\
\text { sample (AOR }=1.66, p=0.639) \\
\text { Rates of coverage not reported. }\end{array}$ \\
\hline
\end{tabular}

${ }^{\text {a}}$ Rates not separated by gender identity (i.e., transgender men vs. transgender women). 
accessed healthcare. Transgender men of color may be less likely to access regular primary care than white transgender men, given that cisgender men of color are less likely than white cisgender men to access primary care. ${ }^{63}$ There is a critical need for studies that address the needs of transgender men of color.

\section{Rates of HIV}

Literature on HIV prevalence largely focused on transgender women. Results from the studies that included transgender men suggest that HIV rates are not elevated among transgender men and are much lower than rates among transgender women.

The majority of studies (18 of 31) used self-report to determine HIV status. Self-report of HIV status likely results in underestimates of HIV prevalence; still, most studies reported extremely high rates of HIV prevalence among transgender women, with reported rates varying from $16 \%$ to more than $50 \%$. Most of these studies were not designed to address true population-based prevalence rates because they used convenience sampling methods or focused on specific subpopulations (i.e., sex workers). There is a dearth of national data on rates of HIV in transgender people, especially transgender women, as most research is limited to large urban areas. One article on the global burden of HIV on transgender women estimates that $21.7 \%$ of transgender women in the United States are HIV positive and most of this risk is associated with condomless sex with cisgender men. ${ }^{17} \mathrm{~A}$ number of recent reviews have addressed the prevalence of HIV specifically in transgender women, finding that, worldwide, transgender women engaged in sex work are at significantly higher risk for contracting HIV than cisgender people engaged in sex work. ${ }^{20}$ There is an estimated worldwide HIV prevalence rate of $19.1 \%$ among transgender women. ${ }^{17}$ Based on the findings from this systematic review and other reviews that included international samples, there are specific populations of transgender women who are at greater risk for contracting HIV. ${ }^{19}$ Being African American is independently associated with increased likelihood of being HIV positive ${ }^{25,30}$ as is engaging in sex work, ${ }^{55}$ illicit drug use, ${ }^{25,36,55}$ and experiencing gender-based violence. $^{12,46}$ Interestingly, one study used a cisgender comparison sample matched for age, race, and socioeconomic status (SES) and found no significant differences in rates of HIV between groups, ${ }^{51}$ highlighting the importance of considering comparison samples when conducting transgender health research. In sum, growing evidence suggests that there is an HIV/ AIDS syndemic among transgender women, such that structural factors and marginalization lead to increased incidence of HIV. ${ }^{8}$

\section{Sexual behavior and HIV}

Both transgender men and women have high rates of sexual practices that increase risk for HIV infection. A study in 2005 found only $29 \%$ of transgender male respondents, and $59 \%$ of transgender female respondents used protection during their last sexual encounter. ${ }^{45}$ Reported rates of condomless receptive anal intercourse (CRAI) vary widely by study, in part due to differences in sample demographics but also in the manner in which CRAI self-reports are assessed. For example, one study reported a $90.9 \%$ lifetime incidence of CRAI, ${ }^{49}$ and two studies found that more than $75 \%$ of their transgender sample reported condomless receptive sex in the last 3 months. ${ }^{35,44}$ However, most studies that assess for CRAI in the last 2-3 months report ranges from $30 \%$ to $50 \%$ among transgender people. ${ }^{24,33,50,57}$

Another study reported higher rates of condomless intercourse among transgender men than women, ${ }^{45}$ although transgender men overall do not show high rates of HIV infection. This may be due to differences in HIV transmission risk between receptive anal and receptive vaginal intercourse, wherein CRAI is associated with an estimated 10-20 times greater risk of HIV contraction than condomless vaginal intercourse, ${ }^{64-66}$ differences between groups in types of sexual partners (commercial sex work, casual sexual partners, or primary partners), or differences in healthcare utilization, as there is some evidence for higher rates of healthcare utilization among transgender men than transgender women. ${ }^{14}$ Future studies should assess differences between the sexual practices and attitudes of transgender men and women to determine why both groups show such high rates of CRI, but only transgender women show high rates of HIV infection.

Several studies also addressed risk factors related to increased likelihood of engaging in CRAI. Factors associated with CRAI include living with a primary sexual partner, having a sexual partner who is an injection drug user, and sexual partner seroconcordance ${ }^{33,41}$ as well as intimate partner violence and substance use. ${ }^{8,31}$ Being HIV positive was also associated with increased likelihood of CRAI, independent of partner status, ${ }^{11,31}$ as was the use of Internet dating websites or apps. ${ }^{55}$ Those with high self-efficacy or self-esteem 
are less likely to engage in CRAI. ${ }^{32,40,43}$ Engaging in CRAI may be a survival tactic for individuals who live at the intersection of multiple marginalized identities marked by social instability and limited access to resources. ${ }^{32}$ In addition to the substantial and growing quantitative literature regarding transgender people and HIV risk behaviors, more qualitative work is needed to better understand the experiences and needs of transgender women engaging in HIV risk behaviors.

\section{HIV screening practices}

The CDC recommends that all people at high risk for HIV infection undergo HIV screening at least annually. ${ }^{67}$ Transgender people undergo HIV screenings at higher rates than the general population. In an analysis of the Massachusetts' 2007-2009 BRFSS, 16.8\% of the transgender survey respondents reported having an HIV test during the last year, compared to only $9.8 \%$ of cisgender respondents who reported having an HIV test during the last year. ${ }^{22}$ In a 2010 study focused on lifetime HIV testing in transgender men living in Boston, $94 \%$ of study participants reported having an HIV test at some point in their life. ${ }^{50}$ Another study in San Francisco found transgender women were more likely to be tested for HIV than cisgender women, ${ }^{28}$ and a study of individuals involved in the Los Angeles House Ball scene found 83\% of participants had been tested for HIV in the last 6 months, although this study did not distinguish transgender people from cisgender people statistically. ${ }^{68}$ Screening for HIV-and other STDs-remains an important tool in attending to the primary care needs of transgender people. This remains true even for HIV-positive individuals. In a large cohort study of transgender women in New York City, there was a substantial risk of incident sexually transmitted infection (STI) following HIV diagnosis, underscoring the importance of frequent STI screening and prevention counseling for individuals who engage in high-risk behavior. ${ }^{69}$

\section{Barriers to HIV care and HIV interventions}

There has been little research addressing transgenderspecific barriers to HIV prevention; much of the current HIV literature among transgender women focuses on behavioral correlates of either CRAI or HIVpositive status. However, a recent qualitative study of a national sample of transgender women identified several barriers to accessing HIV preventive care. These barriers include stigma, being unaware or misinformed about resources, exclusion from relevant clinical research trials, mistrust of the scientific community, and perceived possible HIV-vaccine side effects. Facilitators to accessing necessary preventive resources included increased information and awareness, research staff and providers sensitive to transgender individual's needs, recommendations from a trusted transgenderfriendly healthcare provider, and assistance with basic needs. $^{70}$

There is a small body of research on the effectiveness of various HIV prevention program interventions among transgender populations. ${ }^{43,54,71}$ Recommendations for future HIV harm reduction programs include targeted advertising on Internet hook up sites and attention to the housing status of participants. ${ }^{11,55}$ Housing status is particularly important because research demonstrates an unstable housing environment is associated with lower treatment adherence in HIV-positive transgender women. ${ }^{11,37,38} \mathrm{~A}$ final recommendation is made by Bockting et al. who argue that facilitating interaction between transgender peers in HIV prevention initiatives, in addition to promoting safer sex behaviors, deflects the impact of gender-based abuse and violence. ${ }^{72}$ Given the link between gender-based violence and increased incidence of HIV as well as HIV risk behaviors, reducing gender-based violence is essential to HIV harm reduction initiatives. ${ }^{12,46}$

\section{Cholesterol screening}

The American Heart Association recommends that all adults, beginning at age 20, undergo cholesterol screening every 2 years, with those at a higher risk for heart disease screened more frequently. ${ }^{73}$ In the present review, two studies addressed cholesterol levels and screenings, with both being longitudinal studies investigating gender affirming hormone therapy on transgender people's body mass index (BMI), BP, and lipids. A 2014 chart review study examined cholesterol levels for transgender women following hormone therapy and found that low-density lipoprotein levels resembled cisgender female values, but triglyceride levels were higher than cisgender males and females. High-density lipoprotein levels were not statistically different between transgender women and either cisgender group. The authors conclude that current clinical laboratory reference guidelines for transgender women may not be clinically helpful, as transgender patients in their study did not fall within the established guidelines for cisgender women on several measures, and because these guidelines are based on 
healthy limits for postmenopausal women receiving estrogen hormone therapy. ${ }^{34}$ Meanwhile, Deutsch and colleague's 2015 study suggests that transgender people receiving gender-affirming hormone therapy do not develop abnormal BP or lipids levels in the short term. In this study, gender-affirming hormone therapy was associated with a reduction in BP in transgender women and increased BMI in transgender men. ${ }^{26}$ Taken together, these two studies underscore the importance of hormone level monitoring to guide therapy. More research is needed to address the potential need for clinical reference guidelines relevant to transgender people undergoing gender-affirming hormone therapy.

\section{Tobacco use}

There is a paucity of research on tobacco use in transgender communities, but rates are likely higher than the general population. ${ }^{28}$ A 2009 study of transgender women living in New York City found $50 \%$ of interviewed participants reported current tobacco use. ${ }^{53}$ Furthermore, in an analysis of Massachusetts' 20072009 BRFSS data, transgender people were more likely to report that they were a current smoker $(26 \%)$ than cisgender people (17\%). ${ }^{22}$ In a large study of transgender people living in Virginia, rates of tobacco use were also high. Of the study's 350 eligible survey respondents, $64 \%$ reported tobacco use at some point in their life, $23 \%$ reported having a lifetime problem with tobacco, and $13 \%$ reported a current problem with tobacco use. ${ }^{10}$ In a 2015 study of 241 transgender women in San Francisco, 83\% indicated having smoked a cigarette in the last month. Of these women, $62.3 \%$ reported daily smoking and $51.7 \%$ reported an unsuccessful quit attempt. The data also demonstrated that healthcare, employment, and housing discrimination were positively associated with current smoking status, unsuccessful attempts at smoking cessation, and never having attempted cessation of smoking habits. ${ }^{74}$

These above findings differ from an earlier 20012002 study of transgender people in Boston, which demonstrated no difference in smoking status between transgender and cisgender study populations. ${ }^{51}$ This difference illustrates the importance of comparison populations in transgender healthcare literature. Specifically, differences in findings between studies are likely due to sample characteristics; the Reisner et al. study used an age, race, and SES-matched sample of cisgender individuals seeking care at the same LGBT clinic, whereas other studies, including the BRFSS
Massachusetts survey study, compared transgender people to a large mixed sample of heterosexual people. Given the high rates of tobacco use among cisgender LGB people, ${ }^{75}$ the differences between studies are interesting and suggest that tobacco use rates among transgender people may be higher than the general population, but not higher than rates among cisgender LGB people.

Finally, most studies did not address smoking cessation or provider screenings for smoking status. One study did find that transgender women with a regular healthcare provider were less likely to be current smokers than those without a provider, although this could simply mean that this subset of transgender women has more resources to invest in their long-term health or are more health conscious. ${ }^{56}$ More studies are needed to determine the efficacy of smoking cessation interventions for transgender people.

\section{Pap tests}

A growing body of literature suggests lower rates of Pap tests among transgender men. The U.S. Preventive Services Task Force 2012 guidelines for cervical cancer screening recommend that cisgender women be screened every 3 years starting at age 21 and that women ages 30-65 be screened every 5 years, in combination with HPV testing. ${ }^{76}$ A study of New England FTM transgender men who have sex with cisgender men found $31 \%$ of its respondents had not had a Pap test in the last 12 months. ${ }^{50}$ Chart reviews of transgender men living in New England found they were significantly less likely to be up-to-date on Pap tests compared to cisgender female patients. ${ }^{47,48}$ In addition, recent evidence suggests increased rates of insufficient or unsatisfactory samples for Pap tests in transgender men compared to cisgender women, which could be related to cervical tissue changes following androgen exposure, as well as provider discomfort with performing the examination on transgender men. ${ }^{48}$ The low rate Pap tests among transgender men and assigned-female nonbinary individuals are likely due to discomfort surrounding pelvic anatomy, high rates of trauma compounding gender dysphoria-based discomfort, and lack of access to providers with experience seeing transgender patients. ${ }^{42,48,77}$ Coupled with the high rates of condomless receptive sex among transgender men who have sex with cisgender men, ${ }^{35,44,45}$ transgender men may face significant risks for cervical cancer that remains undetected due to decreased screening. There is an urgent need for interventions 
that focus on the sexual health needs of transgender men, as well as changes in clinic policies that allow transgender men to feel empowered to access sexual healthcare screenings.

\section{Insurance status}

This literature review did not identify any large-scale studies on insurance coverage among transgender people, and we therefore cannot infer overall rates of insurance coverage. The most recent National Transgender Discrimination Survey reports that 19\% of transgender people have no health insurance, which is higher than the general U.S. population. Insurance coverage had a significant impact on primary care access; transgender people without insurance are much more likely to report delaying primary care than those with insurance ( $88 \%$ vs. $39 \%) .{ }^{9}$ In the present literature review, eight studies included observational data about rates of health insurance coverage. ${ }^{10,22-}$ 24,37,48,50,53 These studies indicate that a large number of transgender people remain uninsured. For transgender people who do have insurance, they are more likely than cisgender people to be covered through public options. ${ }^{9,53}$ Given geographic differences in Medicaid expansion, regional differences in health insurance coverage may be more pronounced among transgender people.

\section{Primary care gaps in the literature}

There were no studies that addressed breast or chest tissue screenings, rates of receipt of annual flu shots, or colorectal screenings among transgender people. With regard to breast/chest tissue health, a recent US retrospective study of 5135 transgender people receiving gender-affirming hormone therapy found that hormone treatment in both male- and female-assigned people did not result in a greater incidence of breast cancer compared to the general population. ${ }^{78}$ A qualitative study of six transgender men found that half of participants reported significant discomfort regarding their chest tissue and that half reported "binding" their chest tissue on a regular basis. ${ }^{42}$ However, there is no research literature addressing how discomfort with anatomy may impact access to screenings for transgender people. Transgender women should receive chest tissue screenings following a minimum of 5 years of hormone therapy, regardless of age, and transgender people who undergo bilateral mastectomy, chest reduction, or "top" surgery and still have remaining chest tissue should undergo cancer screenings as recommended for cisgender women. ${ }^{79,80}$ Flu shots are an important component of primary healthcare and are of particular importance among populations with high incidence of HIV/AIDS. ${ }^{81}$ There is no research literature that addresses receipt of flu shots among transgender people, although receipt of flu shots could serve as a simple metric of access to care in future studies. Finally, the lack of studies examining colorectal care highlights another significant gap in the transgender health literature: the inclusion of transgender elders. Most studies in the present review report mean ages between 30 and 40. The health needs of transgender elders are largely unaddressed by the research literature and represent an important area of opportunity for inquiry and intervention.

\section{Conclusion}

By performing a systematic literature review, we identified several opportunities for future research that could improve care for transgender individuals, particularly regarding representation of rural and Southern populations, transgender men of color, and transgender elders. With increasing visibility of transgender people comes a growing ethical imperative for clinicians and researchers to meet the needs of this diverse population. The findings of the present literature review indicate that preventive healthcare among transgender populations is less emphasized than other research areas; even less research has focused on developing health promotion or healthcare utilization interventions to reduce health disparities among transgender people. As the transgender healthcare literature comes of age, more research should focus on developing interventions to serve transgender people, while also considering approaches that include transgender people using participatory designs to ensure that the needs of transgender communities are well represented in the research literature. $^{82}$

\section{Author Disclosure Statement}

No competing financial interests exist.

\section{References}

1. The Sylvia Rivera Law Project. Systems of Inequality: Disproportionate Poverty \& Homelessness. New York, 2011.

2. Coleman E, et al. Standards of care for the health of transsexual, transgender, and gender-nonconforming people, version 7. Int J Transgenderism. 2012;13:165-232.

3. American Academy of Family Physicians. Primary Care. Available at www.aafp.org/about/policies/all/primary-care.html (last accessed 6/1/ 2016). 
4. Starfield B. Improving equity in health: a research agenda. Int J Health Serv. 2001;31:545-566.

5. Kenagy GP. Transgender health: findings from two needs assessment studies in Philadelphia. Health Soc Work. 2005;30:19-26.

6. Xavier JM, Bobbin M, Singer B, Budd E. A needs assessment of transgendered people of color living in Washington, DC. Int J Transgenderism. 2005;8:31-47.

7. Poteat T, Reisner SL, Radix A. HIV epidemics among transgender women. Curr Opin HIV AIDS. 2014;9:168-173.

8. Brennan J, et al. Syndemic theory and HIV-related risk among young transgender women: the role of multiple, co-occurring health problems and social marginalization. Am J Public Health. 2012;102:1751-1757.

9. Grant JM, et al. Injustice at every turn: a report of the National Transgender Discrimination Survey. Washington, DC: National Center for Transgender Equality, 2011.

10. Bradford J, Reisner SL, Honnold JA, Xavier J. Experiences of transgenderrelated discrimination and implications for health: results from the Virginia Transgender Health Initiative Study. Am J Public Health. 2013;103:1820-1829.

11. Fletcher JB, Kisler KA, Reback CJ. Housing status and HIV risk behaviors among transgender women in Los Angeles. Arch Sex Behav. 2014;43:1651-1661.

12. Nuttbrock $L$, et al. Gender abuse and major depression among transgender women: a prospective study of vulnerability and resilience. Am J Public Health. 2014;104:2191-2198.

13. Department of Health and Human Services. National Healthcare Quality Report. Agency for Healthcare Research and Quality, 2011. Available at www.ahrq.gov/research/findings/nhqrdr/nhqr11/index.html (last accessed 8/1/2016).

14. Rachlin K, Green J, Lombardi E. Utilization of health care among femaleto-male transgender individuals in the United States. J Homosex. 2008;54:243-258.

15. Brown A, Rise SM, Rickwood DJ, Parker AG. Systematic review of barriers and facilitators to accessing and engaging with mental health care among at-risk young people. Asia Pac Psychiatry. 2016;8:3-22.

16. Hoffman B. An overview of depression among transgender women. Depress Res Treat. 2014;2014:394283.

17. Baral SD, et al. Worldwide burden of HIV in transgender women: a systematic review and meta-analysis. Lancet Infect Dis. 2013;13:214-222.

18. De Santis JP. HIV infection risk factors among male-to-female transgender persons: a review of the literature. J Assoc Nurses Aids Care. 2009;20: 362-372.

19. Giami A, Le Bail J. HIV infection and STI in the trans population: a critical review. Rev Epidemiol Sante Publique. 2011;59:259-268.

20. Operario D, Soma T, Underhill K. Sex work and HIV status among transgender women: systematic review and meta-analysis. J Acquir Immune Defic Syndr. 2008;48:97-103.

21. U.S. Department of Health and Human Services. Center for Disease Control and Prevention, Centers for Disease Control and Prevention (CDC) Behavorial Risk Factor Surveillance System Survey Data. Atlanta, GA, 2010, p. 143 .

22. Conron KJ, Scott G, Stowell GS, Landers SJ. Transgender health in Massachusetts: results from a household probability sample of adults. Am J Public Health. 2012;102:118-122.

23. Bazargan M, Galvan F. Perceived discrimination and depression among low-income Latina male-to-female transgender women. BMC Public Health. 2012;12:663.

24. Chen S, McFarland W, Thompson HM, Raymond HF. Transmen in San Francisco: what do we know from HIV test site data? AIDS Behav. 2011;15:659-662.

25. Clements-Nolle K, Marx R, Guzman R, Katz M. HIV prevalence, risk behaviors, health care use, and mental health status of transgender persons: implications for public health intervention. Am J Public Health. 2001;91:915-921.

26. Deutsch MB, Bhakri V, Kubicek K. Effects of cross-sex hormone treatment on transgender women and men. Obstet Gynecol. 2015;125:605-610.

27. Edwards JW, Fisher DG, Reynolds GL. Male-to-female transgender and transsexual clients of HIV service programs in Los Angeles County, California. Am J Public Health. 2007;97:1030-1033.

28. Flentje A, Heck NC, Sorensen JL. Characteristics of transgender individuals entering substance abuse treatment. Addict Behav. 2014;39:969-975.
29. Johnson-Jennings MD, et al. Racial discrimination's influence on smoking rates among American Indian Alaska Native two-spirit individuals: does pain play a role? J Health Care Poor Underserved. 2014;25:16671678.

30. Kellogg TA, et al. Incidence of human immunodeficiency virus among male-to-female transgendered persons in San Francisco. J Acquir Immune Defic Syndr. 2001;28:380-384.

31. Nemoto T, et al. HIV risk behaviors among male-to-female transgender persons of color in San Francisco. Am J Public Health. 2004;94:1193-1199.

32. Nemoto $T$, Bodeker $B$, Iwamoto $M$, Sakata $M$. Practices of receptive and insertive anal sex among transgender women in relation to partner types, sociocultural factors, and background variables. AIDS Care. 2014;26:434440.

33. Operario D, Nemoto T, Iwamoto M, Moore T. Unprotected sexual behavior and HIV risk in the context of primary partnerships for transgender women. AIDS Behav. 2011;15:674-682.

34. Roberts TK, et al. Interpreting laboratory results in transgender patients on hormone therapy. Am J Med. 2014;127:159-162.

35. Rowniak S, Chesla C, Rose CD, Holzemer WL. Transmen: the HIV risk of gay identity. AIDS Educ Prev. 2011;23:508-520.

36. Santos GM, et al. Alcohol and substance use among transgender women in San Francisco: prevalence and association with human immunodeficiency virus infection. Drug Alcohol Rev. 2014;33:287-295.

37. Santos GM, et al. HIV treatment cascade among transgender women in a San Francisco respondent driven sampling study. Sex Transm Infect. 2014;90:430-433.

38. Sevelius JM, Carrico A, Johnson MO. Antiretroviral therapy adherence among transgender women living with HIV. J Assoc Nurses AIDS Care. 2010;21:256-264.

39. Stephens SC, Bernstein KT, Philip SS. Male to female and female to male transgender persons have different sexual risk behaviors yet similar rates of STDs and HIV. AIDS Behav. 2011;15:683-686.

40. Sugano E, Nemoto T, Operario D. The impact of exposure to transphobia on HIV risk behavior in a sample of transgendered women of color in San Francisco. AIDS Behav. 2006;10:217-225.

41. Wilson EC, Santos GM, Raymond HF. Sexual mixing and the risk environment of sexually active transgender women: data from a respondentdriven sampling study of HIV risk among transwomen in San Francisco, 2010. BMC Infect Dis. 2014;14:430.

42. Dutton L, Koenig K, Fennie K. Gynecologic care of the female-to-male transgender man. J Midwifery Womens Health. 2008;53:331-337.

43. Golub SA, et al. The role of religiosity, social support, and stress-related growth in protecting against HIV risk among transgender women. J Health Psychol. 2010;15:1135-1144.

44. Kenagy GP. HIV among transgendered people. AIDS Care. 2002;14:127134.

45. Kenagy GP, Hsieh CM. The risk less known: female-to-male transgender persons' vulnerability to HIV infection. AIDS Care. 2005;17:195-207.

46. Nuttbrock L, et al. Gender abuse and incident HIV/STI among transgender women in New York City: buffering effect of involvement in a transgender community. AIDS Behav. 2015;19:1446-1453.

47. Peitzmeier SM, Khullar K, Reisner SL, Potter J. Pap test use is lower among female-to-male patients than non-transgender women. Am J Prev Med. 2014;47:808-812.

48. Peitzmeier SM, Reisner SL, Harigopal P, Potter J. Female-to-male patients have high prevalence of unsatisfactory Paps compared to nontransgender females: implications for cervical cancer screening. J Gen Intern Med. 2014;29:778-784.

49. Reisner SL, et al. HIV risk and social networks among male-to-female transgender sex workers in Boston, Massachusetts. J Assoc Nurses AIDS Care. 2009:20:373-386.

50. Reisner SL, Perkovich B, Mimiaga MJ. A mixed methods study of the sexual health needs of New England transmen who have sex with nontransgender men. AIDS Patient Care STDS. 2010;24:501-513.

51. Reisner SL, White JM, Bradford JB, Mimiaga MJ. Transgender health disparities: comparing full cohort and nested matched-pair study designs in a community health center. LGBT Health. 2014;1:177184.

52. Reisner SL, White JM, Bradford JB, Mimiaga MJ. Sexual risk behaviors and psychosocial health concerns of female-to-male transgender men screening for STDs at an urban community health center. AIDS Care. 2014;26:857-864. 
53. Sanchez NF, Sanchez JP, Danoff A. Health care utilization, barriers to care, and hormone usage among male-to-female transgender persons in New York City. Am J Public Health. 2009;99:713-719.

54. Taylor RD, et al. Girlfriends: evaluation of an HIV-risk reduction intervention for adult transgender women. AIDS Educ Prev. 2011;23:469-478.

55. Benotsch EG, et al. Use of the Internet to meet sexual partners, sexual risk behavior, and mental health in transgender adults. Arch Sex Behav. 2014;45:597-605.

56. Tamí-Maury l, et al. A pilot study to assess tobacco use among sexual minorities in Houston, Texas. Am J Addict. 2015;24:391-395.

57. Ellingson L, Odo C. HIV risk behaviors among Mahuwahine (native Hawaiian transgender women). AIDS Educ Prev. 2008;206:558-569.

58. Light AD, Obedin-Maliver J, Sevelius JM, Kerns JL. Transgender men who experienced pregnancy after female-to-male gender transitioning. Obstet Gynecol. 2014;124:1120-1127.

59. Deutsch MB, Buchholz D. Electronic health records and transgender patients - practical recommendations for the collection of gender identity data. J Gen Intern Med. 2014;30:843-847.

60. Ricketts TC. Rural Health in the United States. New York: Oxford University Press, 1999.

61. Woodberry RD, Smith CS. Fundamentalism et al.: conservative protestants in America. Annu Rev Sociol. 1998;24:25-26.

62. Hasenbush A, et al. The LGBT Divide: A Data Portrait of the South, Midwest, and Mountain States. Los Angeles, The Williams Institute, 2014.

63. Gilbert $\mathrm{KL}$, et al. Visible and invisible trends in black men's health: pitfalls and promises for addressing racial, ethic, and gender inequities in health Annu Rev Public Health. 2016;37:295-311.

64. Leynaert B, Downs AM, De Vicenzi I. Heterosexual transmission of human immunodeficiency virus: variability of infectivity throughout the course of infection. Am J Epidemiol. 1998;148:88-96.

65. Gray RH, et al. Probability of HIV-1 transmission per coital act in monogamous, heterosexual, HIV-1-discordant couples in Rakai, Uganda. Lancet. 2001;357:1149-1153.

66. Padian NS, et al. Heterosexual transmission of human immunodeficiency virus (HIV) in northern California: results from a ten-year study. Am J Epidemiol. 1997;146:350-357.

67. The Center for Disease Control. Revised Recommendations for HIV Testing of Adults, Adolescents, and Pregnant Women in Health-Care Settings. Available at www.cdc.gov/mmwr/preview/mmwrhtml/rr5514a1.htm (last accessed 8/1/2016).

68. Holloway IW, et al. Network correlates of sexual health advice seeking and substance use among members of the Los Angeles House and Ball communities. Health Educ Res. 2014;29:306-318.

69. Pathela $P$, et al. Incidence of sexually transmitted diseases among transgender persons with HIV, New York City, 2000-2010. Sex Transm Dis. 2014;41:118.

70. Andrasik MP, et al. Exploring barriers and facilitators to participation of male-to-female transgender persons in preventive HIV vaccine clinical trials. Prev Sci. 2014;15:268-276.

71. Garofalo R, et al. Life skills: evaluation of a theory-driven behavioral HIV prevention intervention for young transgender women. J Urban Health. 2012;89:419-431.

72. Bockting WO, et al. Stigma, mental health, and resilience in an online sample of the US transgender population. Am J Public Health. 2013;103:943-951.

73. The American Heart Association. Heart Health Screenings. Available at www.heart.org/HEARTORG/Conditions/Heart-Health-Screenings_UCM_ 428687_Article.jsp (last accessed 8/1/2016).

74. Gamarel KE, et al. Minority stress, smoking patterns, and cessation attempts: findings from a community-sample of transgender women in the San Francisco bay area. Nicotine Tob Res. 2015;18:306-313.

75. Hatzenbuehler ML, Keves KM, Hamilton A, Hasin DS. State-level tobacco environments and sexual orientation disparities in tobacco use and dependence in the USA. Tob Control. 2014;23:127-132.

76. USPSTF. Screening for Cervical Cancer. Available at www.uspreventive servicestaskforce.org/uspstf11/cervcancer/cervcancerrs.htm (last accessed 8/1/2016)

77. Bernstein IM, et al. Guys get Pap tests too: developing cervical cancer screening patient outreach materials for female-to-male transgender patients. J Gen Intern Med. 2014;29:104-105.

78. Brown GR, Jones KT. Incidence of breast cancer in a cohort of 5,135 transgender veterans. Breast Cancer Res Treat. 2015;149:191-198.
79. The Center of Excellence for Transgender Health. Screening for Breast Cancer in Transgender Women. Available at http://transhealth.ucsf.edu/ trans?page=guidelines-breast-cancer-women (last accessed 8/1/2016)

80. The Center of Excellence for Transgender Health. Screening for Breast Cancer in Transgender Men. Available at http://transhealth.ucsf.edu/ trans?page=guidelines-breast-cancer-men (last accessed 8/1/2016).

81. Cohen C, et al. Influenza-related mortality among adults aged 25-54 years with AIDS in South Africa and the United States of America. Clin Infect Dis. 2012;55:996-1003.

82. Tervalon M, Murray-Garcia J. Cultural humility versus cultural competence: a critical distinction in defining physician training outcomes in multicultural education. J Health Care Poor Underserved. 1998;9:117-125.

Cite this article as: Edmiston EK, Donald CA, Sattler AR, Peebles JK, Ehrenfeld JM, Eckstrand KL (2016) Opportunities and gaps in primary care preventative health services for transgender patients: a systematic review, Transgender Health 1:1, 216-230, DOI: 10.1089/trgh.2016.0019.

\begin{aligned} & \multicolumn{1}{c}{ Abbreviations Used } \\ & $\mathrm{AIDS}=$ acquired immune deficiency syndrome \\ & $\mathrm{BMI}=$ body mass index \\ & $\mathrm{BP}=$ blood pressure \\ & $\mathrm{BRFS}=$ Behavioral Risk Factor Surveillance System \\ & $\mathrm{CRAI}=$ condomless receptive anal intercourse \\ & $\mathrm{CRI}=$ condomless receptive intercourse \\ & $\mathrm{HIV}=$ human immunodeficiency virus \\ & $\mathrm{HPV}=$ human papillomavirus \\ & $\mathrm{LDL}=$ low-density lipoprotein \\ & $\mathrm{SES}=$ socioeconomic status \end{aligned}

